\title{
RHINOLOGY
}

\section{Evaluation of nasal symptoms in septoplasty patients using SNOT-22}

\section{Valutazione dei sintomi nasali mediante SNOT-22 nei pazienti sottoposti a settoplastica}

\author{
D. DIZDAR ${ }^{1}$, A. BOZAN², S.K. DIZDAR ${ }^{3}$, S. GÖDE ${ }^{4}$, H.C. ALPAY² \\ ${ }^{1}$ Istanbul Kemerburgaz University, Medical Faculty, Department of Otorhinolaryngology, Istanbul, Turkey; ${ }^{2}$ Istanbul \\ Kemerburgaz University, Medical Faculty, Department of Otorhinolaryngology, Tarsus, Turkey; ${ }^{3}$ Hamidiye Sisli \\ Etfal Education and Research Hospital, Istanbul, Turkey; ${ }^{4}$ Ege University, Medical Faculty, Department of \\ Otorhinolaryngology, Izmir,Turkey
}

\begin{abstract}
SUMMARY
The aim of our study is to evaluate the nasal symptoms of patients with indications for septoplasty using the SNOT-22 questionnaire and to investigate the effects of variables such as concha surgery, age, obstructive sleep apnoea (OSA), smoking and asthma on these symptoms. A total of 100 patients were included in the study. Pre-operative and at postoperative month 3, patients were administered the Sinus Nasal Conduct Test (SNOT22). Septoplasty operations were performed by two centres and two otolaryngologists and head and neck surgeons. The patients were divided into two groups according to the surgical procedure of the lower concha, concha shaver group and concha out fractures. The difference in total score between preop and postop was significant in both the shaver and outfracture groups with a difference in total score of 17.85 (46\%). Improvement in symptoms of nasal obstruction was observed with a mean improvement of 0.81 points ( 2.79 points). In our study, there was no significant difference in preop and postop symptom scores in patients who had subcuneal shaved submucous resection with outfracture $(\mathrm{p}=0.861)$. There was no significant difference between preop and postop total scores between asthma, smoking, OSA and non-asthmatics ( $p>0.05)$. There was no correlation between scores and age in either group $(\mathrm{p}>0.05)$. Before septoplasty, the most important symptom was nasal obstruction. Intervention at the inferior turbinate during surgery increases the benefits of septoplasty independently of the surgical technique. Factors such as asthma, OSA, smoking are significantly relevant to symptoms. In those with asthma and OSA, the scores were found to be high both before and after intervention.
\end{abstract}

KEY WORDS: Septoplasty • SNOT-22 • Concha $\bullet$ Out-fracture $\bullet$ Shaver

\section{RIASSUNTO}

Obiettivo del nostro studio è valutare i sintomi nasali dei pazienti con indicazione a settoplastica mediante il questionario SNOT-22 ed investigare gli effetti di alcune variabili, quali la chirurgia della conca, l'età, l'apnea ostruttiva del sonno (OSA), il fumo e l'asma, su questi sintomi. Un totale di 100 pazienti è stato incluso nello studio. Ai pazienti è stato sottoposto il questionario SNOT-22 (Sinus Nasal Conduct Test) preoperatoriamente e post-operatoriamente a distanza di 3 mesi. Gli interventi di settoplastica sono stati eseguiti in due centri e da due otorinolarinoiatri. I pazienti sono stati divisi in 2 gruppi a seconda della procedura chirurgica sul turbinato inferiore: shaving o outfracture. La differenza nel punteggio totale tra preoperatorio e post-operatorio è risultata signiticativa in entrambi i gruppi, con un valore di 17,85 (46\%). Si è osservato un miglioramento dei sintomi da ostruzione nasale con valore medio di 0,81 punti (2,79 punti). Nel nostro studio non è stata riscontrata differenza significativa nei punteggi riguardanti $i$ sintomi preoperatori e postoperatori dei pazienti sottoposti a resezione sottomucosa con outfracture $(p=0,861)$. Non abbiamo evidenziato differenza significativa tra i punteggi totali preoperatori e postoperatori per quanto riguarda asma, fumo, OSA e non-asmatici ( $p>0,05)$. Non abbiamo evidenziato correlazione tra i punteggi e l'età in entrambi i gruppi $(p>0,05)$. Prima della settoplastica il sintomo principale era l'ostruzione nasale. L'intervento sul turbinato inferiore durante la chirurgia aumenta i benefici della settoplastica indipendentemente dalla tecnica chirurgica. Fattori quali asma, OSA, fumo sono significativamente correlati ai sintomi. Nei pazienti con asma e OSA, i punteggi sono risultati superiore sia prima sia dopo l'intervento.

PAROLE CHIAVE: Settoplastica $\bullet$ SNOT-22 • Conca $\bullet$ Outfracture $\bullet$ Shaver

\section{Introduction}

Nasal septum deviation is present in $19-65 \%$ of the population ${ }^{1}$. Dommerby and Tos reported that nasal trauma in childhood causes more septum deviations than in a control group ${ }^{2}$.
Surgical treatment is required when septum deviation causes symptoms of nasal obstruction. However, the efficacy of septoplasty remains controversial. Many questionnaire-based studies have subjectively evaluated the effects of septoplasty on quality of life and nasal symptoms. 
The Nasal Obstruction Septoplasty Effectiveness scale (NOSE) ${ }^{3}$, Sinonasal Outcome Test-20 (SNOT-20) ${ }^{4}$, and Sinonasal Outcome Test-22 (SNOT-22) ${ }^{56}$ are commonly used evaluation methods. Hytönen et al. reported a $55 \%$ improvement in the second postoperative year in patients undergoing septoplasty ${ }^{7}$. Another study that evaluated 200 patients at 6 weeks postoperatively reported improvement in nasal obstruction in $74 \%$ of patients ${ }^{8}$. However, there are also reports of long-term complaints ${ }^{9}$. Lower concha surgery methods are frequently performed with septoplasty, which most frequently affect surgical outcome and improves the symptoms of nasal obstruction ${ }^{10}$. In the literature, there is no single, optimal inferior turbinate surgical method ${ }^{11}$. However, radiofrequency coblation and microdebrider-assisted turbinoplasty are commonly used techniques ${ }^{11}{ }^{12}$.

The multiplicity of variables affecting the success of nasal septal surgery may be the cause of differences in outcomes. To evaluate the nasal symptoms of our septoplasty patients, we examined the effects of surgeon, patient age, obstructive sleep apnoea (OSA), smoking and asthma on symptoms using pre- and post-operative SNOT-22 scores.

\section{Materials and methods}

This study enrolled 118 adults treated between February 2015 and May 2017. Septoplasty was performed on those with nasal obstruction and other nasal symptoms in whom septum deviation and uni/bilateral inferior concha hypertropy was detected by nasal endoscopy. Informed consent was obtained from patients before the operation. All operations were performed under general anaesthesia. During septoplasty, submucosal shaver excision was performed for those with advanced hypertrophy in the lower conchae, and outfracture was performed for those with moderate hypertrophy. Patients were divided in two groups. Patients who underwent nasal septal correction and submucous shaver excision formed the shaver group, patients with outfracture formed outfracture group. Patients with a history of rhinoplasty; patients with prior conchal surgery or endoscopic sinus surgery with septoplasty were excluded from the study. Postoperatively, 19 of the patients were hospitalised for 1 day; the others were discharged the same day. The operations were performed in two centres, by two otolaryngologists and head and neck surgeons. A silicone splint was used in all patients. In addition, 95 patients were treated with Merocel buffer: Merocel-soaked tampons were left in 12 patients for 3 days, while the others were removed after 48 hours. The silicone splints were frequently removed on day $7{ }^{13}$. The SNOT-22 questionnaire, which has been validated in Turkish, was completed 3-9 days preoperatively and at the 3 -month follow-up visit. Patients were asked to score the 22 symptoms on the questionnaire with $0-5$ points $(0$ no problem, 5 worst case) and to identify the five symptoms most important to them. Patients who did not attend the follow-up examination were sent the questionnaire by mail.

Descriptive statistics of patients were summarised as means \pm standard deviation and number. Demographic characteristics were assessed using the independent t-test, chi-squared test, or Fisher's test (Table I); there were no significant differences between the shaver and outfracture groups. Within groups, the significance of the change in responses to each question was assessed using the StuartMaxwell test; P values are given in Table II. The differences between the overall pre- and post-operative scores were assessed using paired t-tests and the difference between two values was assessed using independent t-tests (Table III). The differences between the pre- and postoperative averages according to gender, smokers versus non-smokers and groups with and without comorbidities were assessed using the same methods (Table IV). Statistical significance was set as $p<0.05$. The analyses were

Table I. Demographic data of the groups and comparison with each other.

\begin{tabular}{|c|c|c|c|c|}
\hline & & $\begin{array}{l}\text { Concha shaver } \\
\qquad(\mathrm{N}=45)\end{array}$ & $\begin{array}{l}\text { Concha outfracture } \\
\qquad(\mathrm{N}=55)\end{array}$ & $P$ \\
\hline Age & & $35.6 \pm 13.4$ & $35.7 \pm 12.9$ & 0.990 \\
\hline Sex & $\begin{array}{l}M \\
F\end{array}$ & $\begin{array}{l}24 \\
21\end{array}$ & $\begin{array}{l}33 \\
22\end{array}$ & 0.503 \\
\hline Smoking & $\begin{array}{l}\text { Yes } \\
\text { No }\end{array}$ & $\begin{array}{l}24 \\
21\end{array}$ & $\begin{array}{l}24 \\
31\end{array}$ & 0.334 \\
\hline Asthma & $\begin{array}{l}\text { Yes } \\
\text { No }\end{array}$ & $\begin{array}{c}8 \\
37\end{array}$ & $\begin{array}{c}7 \\
48\end{array}$ & 0.577 \\
\hline OSA & $\begin{array}{l}\text { Yes } \\
\text { No }\end{array}$ & $\begin{array}{c}6 \\
39\end{array}$ & $\begin{array}{c}6 \\
49\end{array}$ & 0.764 \\
\hline
\end{tabular}

OSA: obstructive sleep apnoea. 
performed using STATA/MP11. The study was approved by Adana Numune Education and Research Hospital Ethics Committee (Ethics Committee No: 90).

\section{Results}

The study initially enrolled 118 patients. Eight patients were removed from the study because they did not undergo subconchal surgery and 10 patients were lost to follow-up. Consequently, 100 (91\%) patients (57 men, 43 women) included in the study completed the pre- and postoperative SNOT-22. Of the patients, 15 had asthma, 48 smoked cigarettes and 12 had OSA. In the preoperative polysomnographic evaluation of OSA patients, five were moderate OSA (AHI from 15 to 30) and seven were mild OSA (AHI from 5-15). Fifty-five outfractures were performed with the submucosal resection, while 45 patients had a septoplasty with a lower conchal shaver.

The shaver group comprised 45 patients (24 men, 21 women; mean age $35.6 \pm 13.4$ years), while the outfracture group comprised 55 patients (33 men, 22 women;

Table II. Intra-group comparison of pre-operative and post-operative scores of each symptom.

\begin{tabular}{|c|c|c|}
\hline \multirow[t]{2}{*}{ Symptom } & \multicolumn{2}{|c|}{ Group } \\
\hline & $\begin{array}{l}\text { Concha shaver } \\
\qquad(\mathrm{N}=45)\end{array}$ & $\begin{array}{l}\text { Concha outfracture } \\
\qquad(\mathrm{N}=55)\end{array}$ \\
\hline Hawking & 0.0018 & $<0.001$ \\
\hline Obstruction & $<0.001$ & $<0.001$ \\
\hline Sneezing & 0.0019 & 0.0027 \\
\hline Discharge & 0.0046 & 0.0268 \\
\hline Cough & 0.0015 & 0.0021 \\
\hline Post-nasal drip & 0.0083 & 0.0070 \\
\hline Solid nasal discharge & 0.1219 & 0.0003 \\
\hline Ear stuffiness & 0.1904 & 0.0759 \\
\hline Dizziness & 0.5049 & 0.0051 \\
\hline Otalgia & 0.1750 & 0.0098 \\
\hline Facial pain-pressure & 0.2585 & 0.0162 \\
\hline Loss of smell-taste & 0.0313 & $<0.001$ \\
\hline Sleepiness & 0.0002 & $<0.001$ \\
\hline Wake up during night & 0.0001 & $<0.001$ \\
\hline Good quality of sleep & $<0.001$ & $<0.001$ \\
\hline Wake up tired & $<0.001$ & $<0.001$ \\
\hline Fatigue & $<0.001$ & $<0.001$ \\
\hline Poor work performance & $<0.001$ & 0.0008 \\
\hline Concentration problems & 0.0001 & 0.0016 \\
\hline Irritability-restlessness & 0.0002 & 0.3391 \\
\hline Depression & 0.0337 & 0.0012 \\
\hline Shyness & 0.0018 & 0.0456 \\
\hline
\end{tabular}

Table III. Comparison of pre-operative and post-operative scores between groups and intra-group.

\begin{tabular}{lccc} 
& $\begin{array}{c}\text { Concha shaver } \\
(\mathbf{N}=\mathbf{4 5})\end{array}$ & $\begin{array}{c}\text { Concha outfracture } \\
\mathbf{( N = 5 5 )}\end{array}$ & $\mathbf{P}$ \\
Pre-operative & $38.2 \pm 7.4$ & $38.4 \pm 7,3$ & 0.861 \\
Post-operative & $20.0 \pm 3,509$ & $20.9 \pm 3,2$ & 0.227 \\
Difference & $18.2 \pm 7.8$ & $17.6 \pm 8.8$ & 0.723 \\
P & $<0.001$ & $<0.001$ & \\
\hline
\end{tabular}

mean age $35.7 \pm 12.9$ years). Each group included 24 cigarette smokers and six patients with OSA; there were eight patients with asthma in the shaver group and seven in the outfracture group (Table I). The pre- and postoperative SNOT-22 score difference was 17.85 (46\%). A mean improvement in symptoms of nasal obstruction of 0.81 points was observed, and the greatest improvement was 2.79 points. Age, gender, smoking, asthma and OSA did not differ between the two groups (all $\mathrm{p}>0.05$ ). There was a significant difference $(\mathrm{p}<0.001)$ between the preand postoperative responses to the sadness and frustration questions. There was no significant difference between the pre- and post-operative responses to questions about solid nasal discharge, ear fullness, dizziness, ear pain, face pain or sensation of pressure ( $p>0.05)$ (Table II). In the outfracture group, there were significant differences between the pre- and postoperative responses to all questions, except ear fullness, nervousness, restlessness and aspiration (Table II). There was no significant difference in the pre- and post-operative total scores between the two groups ( $\mathrm{p}=0.861$ ). Additionally, the differences between pre- and post-operative scores did not differ significantly between groups $(\mathrm{p}=0.723)$ (Table III, Fig. 1).

The difference in the pre- and postoperative total scores was not affected by gender, smoking, or OSA within and between groups (all $\mathrm{p}>0.05$ ). In addition, there was no significant correlation between the pre- and post-operative score difference and age in either group $(\mathrm{p}>0.05)$ (Table IV). When all patients were evaluated, there was no significant difference in pre- and post-operative scores between asthmatic and non-asthmatic patients $(\mathrm{p}=0.993$ and $p=0.447$, respectively). No significant difference was found between OSA and non-OSA patients in terms of difference in the total score $(p=0.143$ and $p=0.466$, respectively).

\section{Discussion}

Of the patients participating in the study, 100 (91\%) completed both the pre- and post-operative questionnaires. This rate is higher than that in other studies $(60-76 \%)^{510}$. 


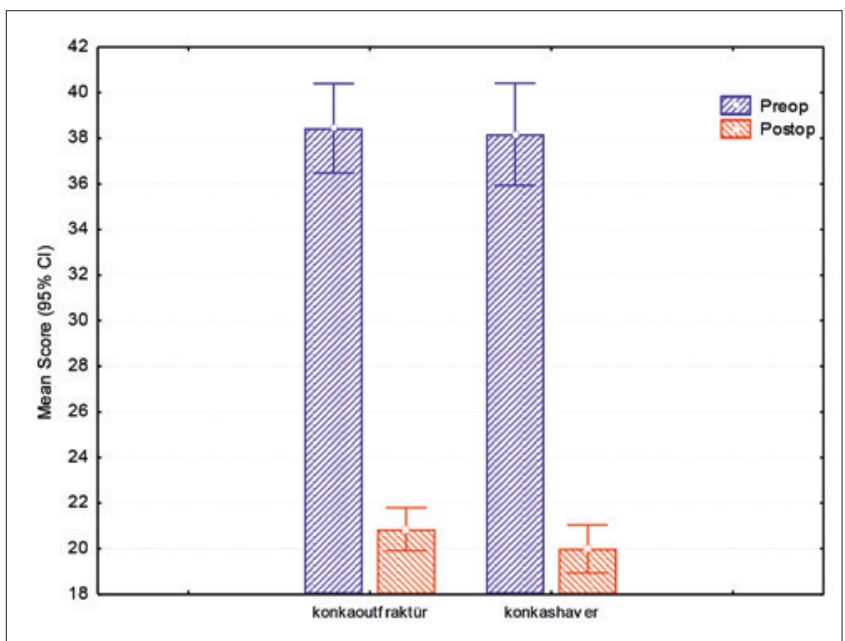

Fig. 1. Total score averages in both groups in pre-operative and post-operative period.

The SNOT-22 was first used to evaluate chronic sinusitis ${ }^{13}$, and has also been used in sepsis ${ }^{56}$. Two septoplasty studies have used the SNOT-22 questionnaire: Buckland et al. ${ }^{6}$ evaluated 40 patients and Maija et al. ${ }^{5}$ evaluated 126 patients at 6 months post-operatively. In our study, the mean preoperative SNOT-22 score was 38.2 (range 21-57), which was higher than SNOT-22 scores in studies of other patients with septal deviation ${ }^{56}$. This may be due to the severe deviation in our patients. The mean postoperative SNOT-22 score was 20.47 (range 14-28), which is consistent with other studies. In SNOT-22 studies conducted in patients with chronic sinusitis and nasal polyps, the mean symptom score decreased by an average of 12.6 and 17.7 points, respectively. The pre- and postoperative total symptom score difference was 4.1 (19\%) and $17(47 \%)$ in SNOT-22 studies performed in the pa- tients with septoplasty ${ }^{614}$. In 40 patients with septal deviation, Buckland et al. ${ }^{6}$ observed the greatest improvement in symptoms of nasal obstruction (mean 2 points), while the other symptoms showed a median improvement of 0.8 points. The difference in our study was 17.85 (46\%). While symptoms improved by 0.81 points on average, and symptomatic improvement in nasal obstruction was 2.79 points.

The mean SNOT-22 score in a healthy population was 9.3 and the lowest significant pre-/post-operative total score difference in a patient population was $8.9^{514}$. In our study, the pre-/post-operative total score difference in 15 patients $(15 \%)$ was less than 8.9 , perhaps because the septal deviation was more moderate in these patients. In our study, two symptoms in the outfracture group and five symptoms in the shaver group did not change significantly postoperatively. There was no significant change in atrophy in either group. This is consistent with other septoplasty studies. In our study, there were no significant differences in the pre- and post-operative symptom scores of patients who underwent shaved submucosal resection and outfracture $(\mathrm{p}=0.861)$.

A study that applied radiofrequency ablation reported that the SNOT scores were lower than those in patients who did not undergo radiofrequency ablation ${ }^{5}$. Another study reported that patients with concha hypertrophy who underwent septoplasty showed significantly improved postoperative nasal obstruction symptoms ${ }^{11}$. In conclusion, although there was improvement in the symptoms of patients who underwent septoplasty and lower concha surgery, there was no difference according to the surgical techniques used.

The symptoms of nasal obstruction are greater in asthmatics than in non-asthmatics ${ }^{15}$. Nasal obstruction can also

Table IV. Pre-operative and post-operative score difference in relation to gender, smoking and OSA.

\begin{tabular}{|c|c|c|c|c|}
\hline & & $\begin{array}{l}\text { Concha shaver } \\
\qquad(\mathrm{N}=45)\end{array}$ & $\begin{array}{l}\text { Concha outfracture } \\
\qquad(\mathrm{N}=55)\end{array}$ & $P$ \\
\hline Sex & $\begin{array}{l}M \\
F\end{array}$ & $\begin{array}{l}19.0 \pm 6.3 \\
17.2 \pm 9.3\end{array}$ & $\begin{array}{l}18,787 \pm 7,983 \\
15.772 \pm 9.734\end{array}$ & $\begin{array}{l}0.914 \\
0.617\end{array}$ \\
\hline P & & 0.457 & 0.214 & \\
\hline Smoking & $\begin{array}{l}\text { Yes } \\
\text { No }\end{array}$ & $\begin{array}{l}18.4 \pm 6.0 \\
17.9 \pm 9.7\end{array}$ & $\begin{array}{l}17.9 \pm 9.1 \\
17.4 \pm 8.7\end{array}$ & $\begin{array}{l}0.793 \\
0.845\end{array}$ \\
\hline P & & 0.800 & 0.829 & \\
\hline OSA & $\begin{array}{l}\text { Yes } \\
\text { No }\end{array}$ & $\begin{array}{l}15.2 \pm 5.3 \\
18.6 \pm 8.1\end{array}$ & $\begin{array}{c}13.3 \pm 9.2 \\
18.102 \pm 8.7\end{array}$ & $\begin{array}{l}0.680 \\
0.766\end{array}$ \\
\hline$P$ & & 0.316 & 0.211 & \\
\hline Age & Correlation & -0.0861 & -0.0902 & \\
\hline$P$ & & 0.5737 & 0.5126 & \\
\hline
\end{tabular}

OSA: obstructive sleep apnaea 
lead to worsening of asthma. In our study, 15 patients had asthma. As in another study using the SNOT-20 questionnaire ${ }^{4}$, there was no significant difference in the pre- and post-operative symptom scores between asthmatic and non-asthmatic patients. However, asthmatics had more symptoms than non-asthmatics. Many studies have reported that young populations benefit more from septoplasty ${ }^{16}$. However, there was no correlation between the changes in postoperative symptoms and age in our study. Additionally, our study included $12(12 \%)$ patients with OSA. There was no significant difference in SNOT-22 scores between OSA and non-OSA patients after septoplasty. However, as in asthmatics, the symptom scores were higher in the OSA patients than in the non-OSA patients. After surgery, three OSA patients reported using continuous positive airway pressure (CPAP). This may be due to their relatively low preoperative apnea hypopnea index (AHI) and the reduced oropharyngeal obstruction of patients who discontinued CPAP use. However, since there were no data to evaluate this and no postoperative polysomnography data, we cannot comment on OSA patients. Although both groups showed improvement in our study, there are reports that the outcome of successful septoplasty worsens in the long term ${ }^{9}$. Therefore, long-term follow-up is needed.

\section{Conclusions}

Before septoplasty, the most important symptom was nasal obstruction. Intervention involving the inferior turbinate during surgery increases the benefits of septoplasty independently of the surgical technique. Although factors such as asthma, OSA, smoking and age did not significantly affect symptom outcomes, pre- and postoperative scores were higher in those with asthma and OSA. Therefore, it is important to consider these diseases before septoplasty and inform patients accordingly.

\section{Conflict of interest statement}

None declared.

\section{References}

Hatipoglu HG, Cetin MA, Yuksel E. Nasal septal deviation and concha bullosa coexistence: CT evaluation. B-ENT 2008;4:227-32.

2 Zielnik-Jurkiewicz B, Olszewska-Sosinska O. The nasal septum deformities in children and adolescents. Int J Pediatr Otorhinolaryngol 2006;70:731-6.

3 Stewart MG, Witsell DL, Smith TL, et al. Development and validation of the nasal obstruction symptom evaluation (NOSE) scale. Otolaryngol Head Neck Surg 2004;130:157-63.

4 Bugten V, Nilsen AH, Thorstensen WM, et al. Quality of life and symptoms before and after nasal septoplasty compared with healthy. BMC Ear Nose Throat Disord 2016;16:13.

5 Hytönen ML, Lilja M, Mäkitie AA, et al. Does septoplasty enhance the quality of life in patients? Eur Arch Otorhinolaryngol 2012;269:2497-503.

6 Buckland JR, Thomas S, Harries PG. Can the sino-nasal outcome test (SNOT-22) be used as a reliable outcome measure for successful septal surgery? Clin Otolaryngol 2003;28:43-7.

7 Hytönen M, Blomgren K, Lilja M, et al. How we do it: septoplasties under local anaesthetic are suitable for short stay surgery; the clinical outcomes. Clin Otolaryngol 2006;31:64-8.

8 Arunachalam PS, Kitcher E, Grayy J, et al. Nasal septal surgery: evaluation of symptomatic and general health outcomes. Clin Otolaryngol 2001;26:367-70.

9 Cantone E, Ricciardiello F, Oliva F, et al. Septoplasty: is it possible to identify potential "predictors" of surgical success? Acta Otorhinolaryngol Ital 2018;38:528-35.

10 Magliulo G, Iannella G, Ciofalo A, et al. Nasal pathologies in patients with obstructive sleep apnoea. Acta Otorhinolaryngol Ital 2019 Mar 25. doi: 10.14639/0392-100X-2173 [Epub ahead of print].

11 Acevedo JL, Camacho M, Brietzke SE. Radiofrequency ablation turbinoplasty versus microdebrider-assisted turbinoplasty: a systematic review and meta-analysis. Otolaryngol Head Neck Surg 2015;153:951-6.

12 Cingi C, Ure B, Cakli H, et al. Microdebrider-assisted versus radiofrequency-assisted inferior turbinoplasty: a prospective study with objective and subjective outcome measures. Acta Otorhinolaryngol Ital 2010;30:138-43.

13 Hanc1 D, Altun H, Sahin E, et al. Turkish translation, cross-cultural adaptation and validation of the SinoNasal Outcome Test (SNOT)-22. ENT Updates 2015;5:51-7.

14 Hopkins C, Gillett S, Slack R, et al. Psychometric validity of the 22-item sinonasal outcome test. Clin Otolaryngol 2009;34:447-54

15 Fokkens WJ, Lund VJ, Mullol J, et al. European position paper on rhinosinusitis and nasal polyps. A summary for otorhinolaryngologists. Rhinology 2012;50:1-12.

16 Gandomi B, Bayat A, Kazemei T. Outcomes of septoplasty in young adults, the nasal obstruction septoplasty effectiveness study. Am J Otolaryngol 2010;31:189-92.

Received: March 27, 2018 - Accepted: May 27, 2018

How to cite this article: Dizdar D, Bozan A, Dizdar SK, et al. Evaluation of nasal symptoms in septoplasty patients using SNOT-22. Acta Otorhinolaryngol Ital 2019;39:98-102. https://doi.org/10.14639/0392-100X-2061

Address for correspondence: Denizhan Dizdar, Istanbul Kemerburgaz University, Medical Faculty, Department of Otorhinolaryngology, Istanbul, Turkey. Tel. +90 5555476856. Fax +90 0212 2893647. E-mail: denizhandizdar@hotmail.com 